\title{
El género Calceolaria (Calceolariaceae) en el departamento de Lima-Perú
}

\section{Genus Calceolaria (Calceolariaceae) in Lima department, Peru}

Pamela Puppo'

1 Universidad Nacional Agraria La Molina. Av. La Molina s/n, La Molina Lima. Email: p puppo@hotmail.com

Presentado: 23/03/2006 Aceptado: $\quad 04 / 07 / 2006$

\begin{abstract}
Resumen
Calceolaria cuenta con un total de 29 especies para Lima. Estas especies pertenecen a dos subgéneros y trece secciones del género. En el presente trabajo Calceolaria rivularis es mencionada por primera vez para este departamento. Calceolaria bicrenata, $C$. inflexa, C. linearis, $C$. neglecta, $C$. pulverulenta y $C$. scabra, no han sido recolectadas en Lima hace mas de cincuenta años, y las colecciones existentes para este departamento no se encuentran en herbarios nacionales. La mayoría de especies habitan estepas de gramíneas con arbustos dispersos, entre los 3000 - $3900 \mathrm{~m}$; cinco habitan en lomas, pero solo una ( $C$. dichotoma) está restringida a esta formación. Se proporciona una clave, ilustraciones que ayuden a la determinación, y breves descripciones de cada especie. Se incluyen breves comentarios a la diversidad de Calceolaria en Perú, nombres comunes y usos conocidos.

Palabras clave: Calceolaria, Calceolariaceae, taxonomía, Lima, Perú

\section{Abstract}

Calceolaria has 29 species in Lima. These species belong to two subgenus and thirteen sections of the genus. Calceolaria rivularis is first reported for this department. Calceolaria bicrenata, $C$. inflexa, C. linearis, C. neglecta, C. pulverulenta and C. scabra, have not been collected in Lima for more than fifty years, and the existing collections for this department are not in national herbariums. Most of the species are found in grass steppe with dispersed bushes, between 3000-3900 m; five species grow in lomas, and only one ( $C$. dichotoma) is restricted to this formation. A key, drawings and short descriptions are provided for these species. Brief comments about the genus diversity in Peru, common names and uses are also included.
\end{abstract}

Key words: Calceolaria, Calceolariaceae, taxonomy, Lima, Peru

\section{Introducción}

Calooolaria L.junto con Jovellana Ruiz \& Pav. y Stemotria Wettst. $\&$ Harms, antes parte de la tribu Calceolarieae de las Scrophulariaceae s.l., constituyen desde hace unos años la familia Calceolariaceae (Olmstead, 2001; Fischer, 2004). C alceolaria posee flores bilabiadas con labio inferior sacciforme provisto generalmente con un tejido secretor de aceites denominado elaióforo (Vogel, 1974). Este género comprende cerca de 181 especies en el neotrópico, la mayoría de las cuales crecen en los Andes (Molau, 1988) y alcanzan su más alta diversidad en el norte del Perú, especialmente en el departamento de Cajamarca (Molau \& Sánchez, 1986). En este sentido, Molau (1988) enfatizó la importancia de la deflexión de Huancabamba como un evento de especiación fundamental para el género. Esto ha sido corroborado filogenéticamente por Andersson (2006).

Entre las revisiones de este género para el Perú, Pennell (1945) describe las C alooolaria del sur del Perú, para los departamentos de Cusco y Puno; además, publica en 1951 una especie nueva para Amazonas. López Guillén (1968) trata sólo la sección A posecos (ahora sección C aloeolaria) en el Perú; incluye especies que no corresponden a la sección y describe numerosas especies y subespecies nuevas basadas en variaciones irrelevantes en la forma de las anteras. Asimismo, en su trabajo de 1969 describe varias especies que no corresponden a esta sección y no proporciona clave alguna para su determinación. Edwin (1970) da a conocer varias especies nuevas para el Perú, y en 1971 hace la revisión del género como parte de las Scrophulariaceae en Flora of Peru. Molau \& Sánchez (1986) se ocuparon del estudio taxonómico de las $\mathrm{C}$ alooolaria de Cajamarca, y proveen claves para determinar las 45 especies presentes en ese departamento. En cuanto a Lima, el total de especies reportadas por Molau (1988) y Brako \& Zarucchi (1993) fue de 28. Finalmente, Puppo (2005) realizó la revisión más reciente, aunque trata sólo las $\mathrm{C}$ aloeolaria que habitan en la provincia de Canta.

Por ser $C$ alooolaria un género numeroso, está subdividido en secciones. Las secciones listadas en el Anexo 1 se diferencian principalmente por el hábito, morfología foliar e indumento; y en algunos casos, por la forma de la corola y anteras. La sección Scapiflorae por ejemplo, se reconoce por su hábito en roseta; mientras que la sección Polydada se caracteriza por tener ramas divaricadas. Las secciones E rioides, L obatae, Parvifoliae, Revolutae, Saliafolia, Teucriifolia y U rtiopsis se reconocen por la forma de las hojas e indumento; la sección V erticillatae por la forma de la corola; $y$ las secciones $C$ alooelaria y Micranthera por la forma de los estambres. Para la identificación de especie, la morfología floral es esencial, sobretodo la forma de la corolay de las anteras.

El presente trabajo constituye una ampliación de la revisión realizada por Puppo (2005) para las especies de la provincia de Canta. En el presente trabajo se describen las 29 especies presentes en Lima, incluyendo a C. rivularis como nuevo reporte. Se proporciona una clave, ilustraciones que ayuden a la determinación, y breves descripciones de cada especie. 


\section{Materiales y Métodos}

El departamento de Lima se encuentra ubicado entre las coordenadas 1016'18"-13019'16" Sy 75030'18"-77053'02" W, frente a las costas del océano Pacífico (Fig. 1). Este departamento está dividido políticamente en diez provincias: Barranca, Cajatambo, Cañete, Canta, Huaral, Huarochirí, Huaura, Lima, Oyón y Yauyos (datos geográficos tomados del INEI).

Weberbauer (1945) distinguió diversos tipos de formaciones vegetales para Lima, tanto en la costa como en la vertiente occidental. D e acuerdo a lo observado, Calooolaria habitaría en formaciones de lomas, en estepa de gramíneas con arbustos dispersos y puna.

Este trabajo se basa principalmente en observaciones llevadas a cabo en materiales depositados en los herbarios: MO, MO L y USM; adicionalmente, se efectuaron algunas salidas de campo entre los años 2004 y 2005. Las medidas mencionadas fueron tomadas tanto de material fresco como seco. Además se indican en negrita los caracteres diagnósticos para cada especie.

La lista de material revisado no se incluyó porfalta de espacio, si el lector estuviera interesado en revisarla podrá solicitarla al autor.

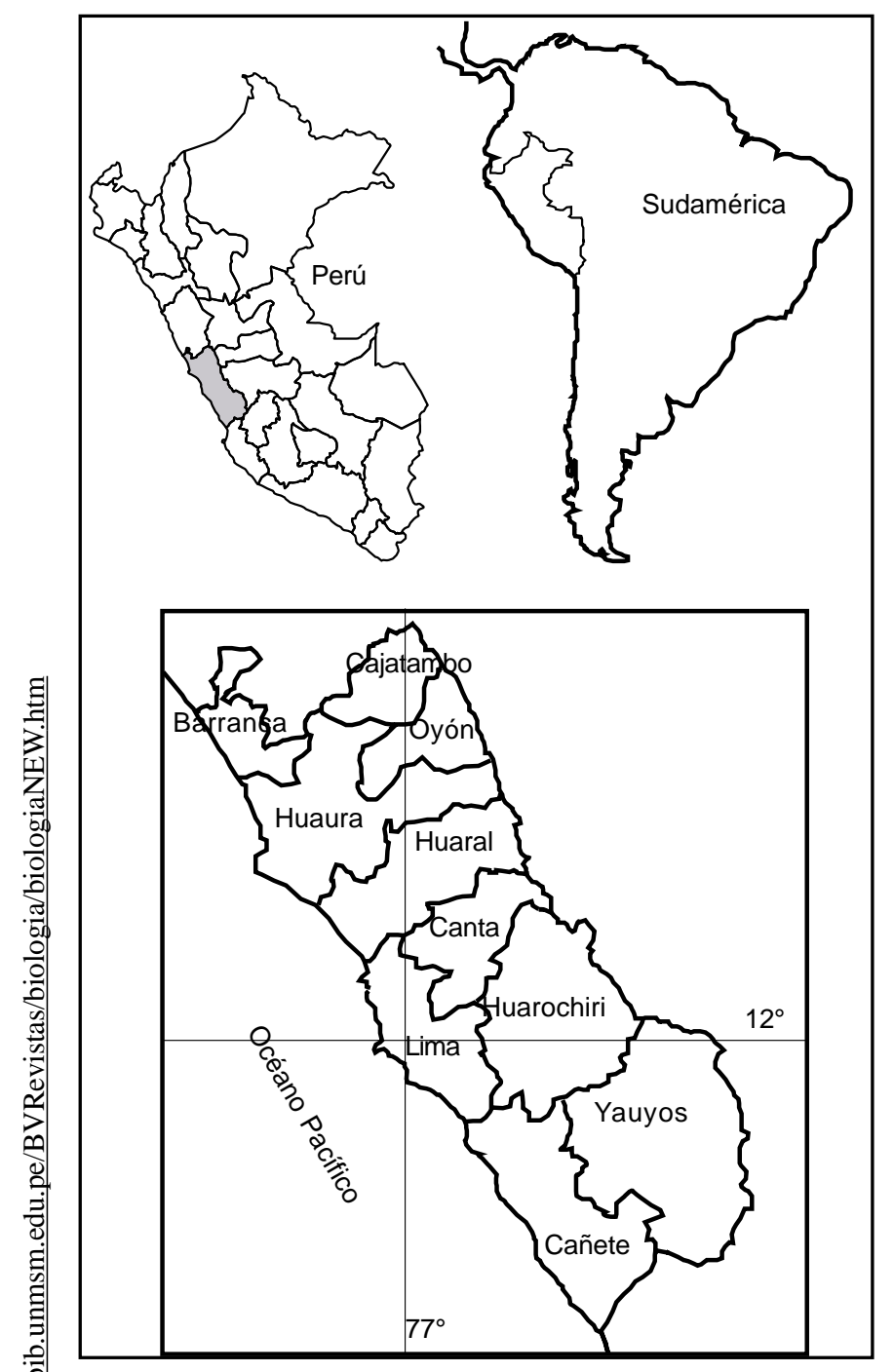

Figura 1. Mapa del departamento de Lima mostrando las provincias.

\section{Resultados}

En total se registraron 29 especies pertenecientes a dos subgéneros y trece secciones del género Calcoolaria (Anexo 1).

\section{Tratamiento taxonómico}

\section{Calceolaria L.}

Hierbas anuales o perennes, subarbustos 0 arbustos. Hojas simples, opuestas y decusadas o ternadas, raro alternas. Inflorescencia usualmente en cimas, en algunas especies flores solitarias. Cáliz 4-partido. Corola bilabiada, usualmente amarilla; labio superior formado por las 2 piezas corolinas adaxiales; labio inferior formado por las 3 piezas corolinas abaxiales, sacciforme y de mayor tamaño que el labio superior, normalmente con una zona de tricomas glandulares secretores de aceites conocida como elaióforo. Estambres 2, anteras con dehiscencia longitudinal. Ovario bilocular, bicarpelar, súpero 0 semiínfero; estilo simple, capitado o inconspicuo. Fruto cápsula pluriseminada, dehiscente distalmente en 4 valvas. Semillas pequeñas, casi lineares, elipsoides y algo recurvadas, testa ornamentada, con costillas longitudinales.

\section{Clave para las especies}

1. Hierbas, subarbustos o arbustos xerofíticos, hojas simples o lobadas; conectivo de las anteras inconspicuo

1. Hierbas higrófitas; hojas pinnatífidas, pinnatisectas o pinnadas; conectivo de las anteras conspicuo, separando ambas tecas 2

2. Teca anterior de los estambres fértil (Fig. 3: X,XII,XIII, XV) 4

2. Teca anterior de los estambres estéril (Fig. 3: XI,XIV) 3

3. Conectivo de las anteras prolongado y con un diente dorsal (Fig. 3, XIV)

C. tripartita

3. Conectivo de la anteras prolongado sin diente (Fig. 3, XI)

C. chelidonioides

4. Conectivo mayor de $2 \mathrm{~mm}$ long., con un diente dorsal (Fig. 3, XV) C. rivularis

4. Conectivo menor de 1,9 mm long., sin diente dorsal (Fig. 3: $\mathrm{X}, \mathrm{XII}, \mathrm{XIII})$

5. Teca anterior menor de $0,8 \mathrm{~mm}$ long. (Fig. 3, XIII) C. tenuis

5. Teca anterior mayor de 0,9 mm long. (Fig. 3: X,XII) 6

6. Teca anterior de 0,9-1,1 mm long.; conectivo de 1-1,5 mm long. (Fig. $3, \mathrm{XII}$ C. pinnata

6. Teca anterior de 1,6-1,8 mm long.; conectivo de 0,1-0,3 mm long. (Fig. $3, \mathrm{X}$ ) C. annua

7. Hierbas acaules; hojas en rosetas; flores solitarias C. scapiflora

7. Hierbas o arbustos con entrenudos manifiestos; hojas opuestas y decusadas, ternadas o alternas; flores en cimas 8

8. Plantas escandentes, ramas divaricadas C. inflex a

8. Plantas erectas, ramas no divaricadas 9

9. Hojas no lineares, más de 3,1 cm long. y 5,1 mm lat. 11

9. Hojas lineares, menos de $3 \mathrm{~cm}$ long. y $5 \mathrm{~mm}$ lat. $\quad 10$

10. Hojas alternas, corola tipo A (Fig. 2), estambres totalmente dehiscentes (Fig. 3, I)

C. linearis

10. Hojas opuestas y decusadas, corola tipo E (Fig. 2), estambres no dehiscentes a través del conectivo (Fig. 3, VIII)

C. rupestris

11. Filamentos de los estambres más cortos que las anteras (Fig. 3, I-VI, VIII-IX) 

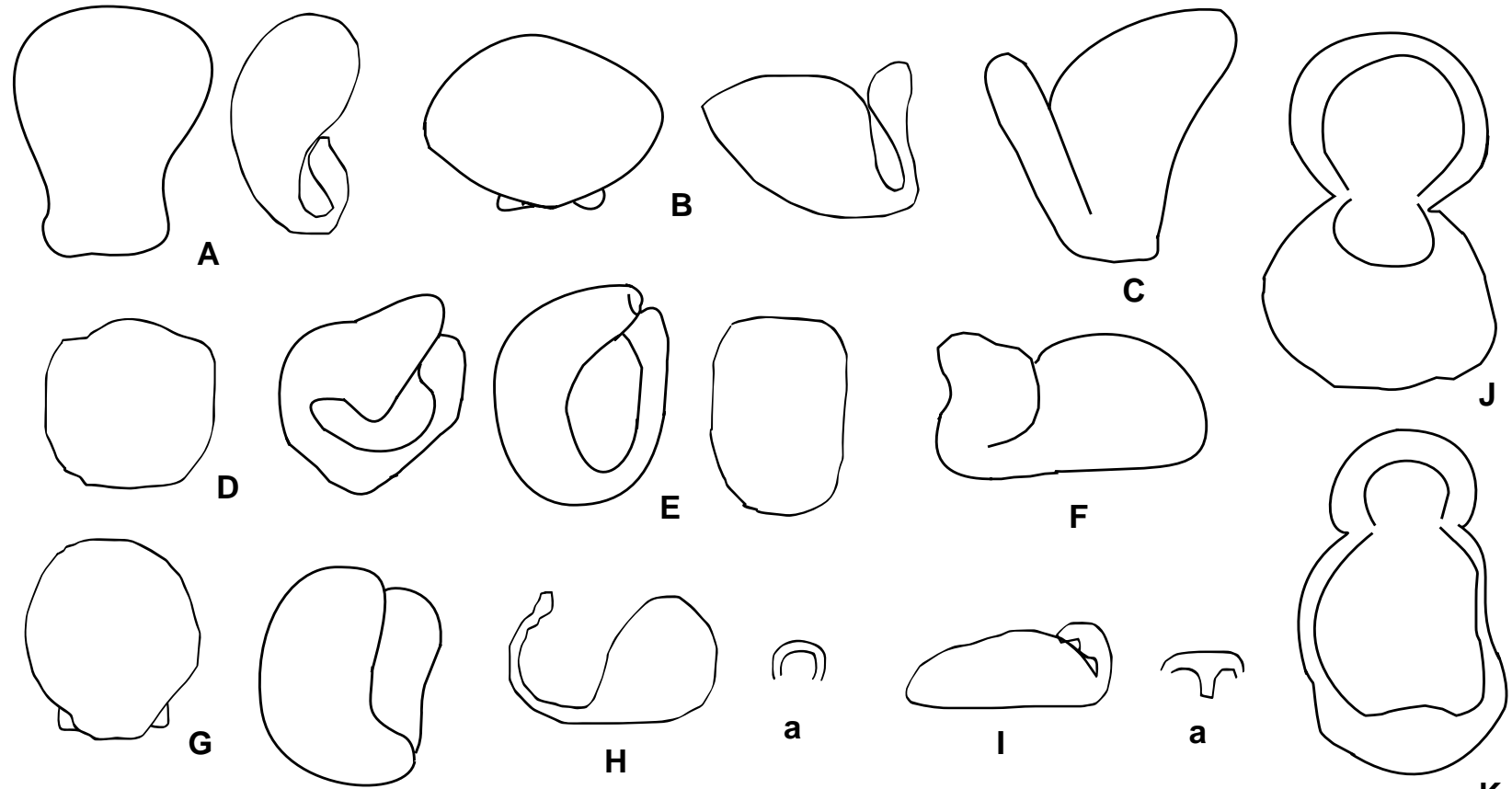

Figura 2. Tipos de corola en Calceolaria usados en la clave. A -I: flores cerradas, con elaióforo. J, K: flores abiertas, sin elaióforo. Dibujo original del autor.

11. Filamentos de los estambres varias veces más largos que las anteras (Fig. 3, VII)

12. Labio superior e inferior de la corola subequilongos; estambres y estilo inclusos en el labio inferior (Fig. 2, C)

C. utricularioides

12. Labio superior de la corola de menor tamaño que el inferior, acuminado; estambres y estilo inclusos en el labio superior (Fig. 2, I a)

C. dichotoma

13. Labio superior de la corola conspicuo, mayor de $2.1 \mathrm{~mm}$ long. 14

13. Labio superior de la corola reducido a una lengüeta menor de 2 $\mathrm{mm}$ long. (Fig. 2, $\mathrm{H} \mathrm{a}$ )

C. angustiflora

14. Hojas enteras, aserradas, biserradas, crenadas o dentadas, corola tipo A, B, E, G, K (Fig. 2)

14. Hojas lobadas, corola tipo D (Fig. 2)

15. Anteras sagitadas (Fig. 3, II)

C. lobata

15. Anteras divaricadas (Fig. 3, I)

16

16. Hojas membranáceas, más de 1,5 cm lat.; márgenes lobulados, planos; pubescencia blanca.

C. hispida

16. Hojas subcoriáceas, menos de 1,4 cm lat.; márgenes profundamente lobados, revolutos; pubescencia marrón.

C. incrum

17. Hojas membranáceas o subcoriáceas, no resinosas, pubescentes 20

17. Hojas coriáceas, resinosas, glabras.

18

18. Corola tipo E (Fig. 2), anteras mayores de $3,8 \mathrm{~mm}$ long. C. visosa

18. Corola tipo G (Fig. 2), anteras menores de 3,5 mm long. 19

19. Sépalos triangulares, 3-4,9 mm long., glabros

C. deflex a ssp. deflex a

19. Sépalos ovados, 5-6 mm long., con un reborde tomentoso en la superficie interna

C. nivalis ssp. cerasifolia

20. Hojas mayores de $1,6 \mathrm{~cm}$ long.

24

20. Hojas menores de $1,5 \mathrm{~cm}$ long.

21. Anteras de los estambres totalmente dehiscentes (Fig. 3, I)

21

21. Anteras de los estambres dehiscentes hasta el conectivo (Fig. 3, IX)
22. Hojas coriáceas, enteras en el extremo proximal

C. pulverulenta

22. Hojas membranáceas, completamente crenadas

C. scabra

23. Hojas crenadas con 3-4 crenas por lado, cuneadas en la base, cáliz agudo 0 acuminado $\quad$ C. cuneiformis ssp. cuneiformis

23. Hojas crenadas con 6-11 crenas por lado, redondeadas o truncadas en la base, cáliz obtuso

C. neglecta

24. Corola siempre tipo A (Fig. 2); anteras menores de $3 \mathrm{~mm}$ long. 27

24. Corola E o K (Fig. 2); anteras mayores de $3 \mathrm{~mm}$ long. 25

25. Corola abierta, sin elaióforo (Fig. 2, K) $\quad$ C. aperta ssp. aperta

25. Corola cerrada, con elaióforo (Fig. 2, E)

26

26. Hojas opuestas y decusadas, envés blanco lanoso; corola totalmente amarilla

C. bicrenata

26. Hojas ternadas, envés blanquecino o verde; corola mitad blanca, mitad amarilla C. biolor

27. Hojas elípticas, dentadas; corola totalmente amarilla C. glauca

27. Hojas ovadas, aserradas o biserradas; corola amarilla con manchas moradas

28

28. Hojas opuestas y decusadas, márgenes aserrados C. virgata

28. Hojas ternadas, márgenes biserrados

C. rugulosa

\section{Calceolaria angustiflora Ruiz \& Pav.}

Arbusto o subarbusto xerófito, erecto. Hojas ternadas, subcoriáceas, simples, ovadas; márgenes aserrados o biserrados. Flores dispuestas en cimas multifloras. Corola amarillo intenso con una mancha rojiza; labio superior reducido a una pequeña lengüeta (Fig. 2, H a); elaióforo presente. Anteras amarillas, tecas divaricadas (Fig. 3, I).

En cuanto a su distribución en Lima, ha sido mencionada para las provincias de Canta, Huarochirí, Huaura, Limay Yauyos. Habita en los valles interandinos entre los 1800-3200 m. y en algunas formaciones de lomas como Lachay o Lurín entre los 
200-700 m. Además, se encuentra en los departamentos de Ancash, Arequipa, Cajamarca, La Libertad y Moquegua.

\section{Calceolaria annua Edwin}

Hierba higrófita, erecta. Hojas opuestas y decusadas, membranáceas, pinnatífidas o pinnadas; márgenes dentados. Flores en cimas paucifloras, en individuos poco desarrollados simulando flores solitarias. Corola amarillo claro; elaióforo presente (Fig. 2, B). Anteras amarillas, teca posterior 2-2,2 mm long., teca anterior 1,6-1,8 mm long., conectivo $0,1-0,3 \mathrm{~mm}$ long., sin diente (Fig. 3, X).

En Lima ha sido mencionada en Canta y Huarochirí. Habita en las vertientes occidentales de los andes, siempre cerca de cursos de aguas, entre los 2400-4300 m. Es endémica de los departamentos de Ancash y Lima.

\section{Calceolaria aperta Edwin subsp. aperta}

Subarbusto 50-100 cm alto, erecto; ramas distales incanas o lanosas. Hojas opuestas y decusadas, membranáceas, simples, ovadas; márgenes aserrados o biserrados. Flores en cimas multifloras. Corola abierta, amarillo-naranja; sin elaióforo (Fig. 2, K). Anteras bicoloras, mitad amarillas, mitad marrónvioláceas (Fig. 3, VI).

Mencionada para la provincia de Canta en Lima en donde ha sido recolectada sólo en Lachaqui. Habita en bordes de chacray terrenos disturbados, entre los 3000-3800 m. Es endémica de Ancash y Lima.

Esta especie posee otra subespecie deanteras completamente marrones conocida sólo en Cajamarca.

\section{Calceolaria bicolor Ruiz \& Pav.}

Arbusto o subarbusto, erecto. Hojas ternadas, membranáceas, simples, ovadas; márgenes aserrados 0 biserrados. Flores en cimas multifloras. Corola amarillo con blanco; elaióforo presente (Fig. 2, E). Anteras amarillas, tecas divaricadas (Fig. 3, I).

En Lima ha sido mencionada para las provincias de Canta, Huaral, Huarochirí y Yauyos. Habita en valles interandinos, entre los 2500-3900 m. Además de Lima, se encuentra en los departamentos de Ancash, Huánuco, La Libertad y Pasco.

\section{Calceolaria bicrenata Ruiz \& Pav.}

Hierba, subarbusto 0 arbusto, erecto o escandente. Hojas opuestas y decusadas, membranáceas, simples, ovadas; márgenes bicrenados o biserrados. Flores en cimas multifloras. Corola amarilla, elaióforo presente (Fig. 2, E). Anteras amarillas 0 marrón claras, tecas divaricadas (Fig. 3, IV).

Esta especiefue recolectada en Huarochirí y mencionada también para Cajatambo. Su distribución altitudinal varía entre los 2500-3750 m. Además de Lima, ha sido mencionada para los departamentos de Amazonas, Ancash, Cajamarca, Huánuco,
Lambayeque, La Libertad y Pasco.

\section{Calceolaria chelidonioides Kunth}

Hierba erecta. Hojas opuestas y decusadas, membranáceas, pinnatisectas o pinnadas; márgenes aserrados. Flores en cimas paucifloras. Corola amarilla; elaióforo presente(Fig. 2, B). Anteras con tecas anteriores abortadas, conectivo elongado sin diente (Fig. 3, XI).

En Lima ha sido mencionada en las provincias de Canta, Huaral, Huarochiń y Lima. Frecuente en valles interandinos siempre cerca de cursos de agua, entre los 2700-3400 m.; rara en formaciones de lomas (entre los 100-200 m). En el Perú se encuentra también en los departamentos de Ancash, Arequipa, Ayacucho, Cajamarca, Cusco, Huánuco, Huancavelica, Junín, Moquegua, Piura y Puno.

\section{Calceolaria cuneiformis Ruiz \& Pav. subsp. cuneiformis}

Arbusto pequeño, erecto y muy ramificado. Hojas 6-11 mm long. x 3-7 mm lat., opuestas y decusadas (algunas parecen fasciculadas), subcoriáceas, simples, ovadas, algo rugosas; márgenes marcadamente crenados, 3-4 dientes por lado; haz verde, envés canescente. Flores en cimas terminales multifloras. Corola amarilla; elaióforo presente (Fig. 2, A). Anteras amarillas o marrón amarillentas, tecas divaricadas, totalmente dehiscentes (Fig. 3, I).

Mencionada en Lima para las provincias de Cajatambo, Cantay Huarochirí, entre los 1800-4000 m. En el Perú también en Ancash, Huánuco, Huancavelica, Junín y La Libertad.

C. aneiformis subsp. x erophila se diferencia en la forma de las hojas y está mencionada para el sur del Perú, en los departamentos de Ayacucho y Arequipa.

\section{Calceolaria deflexa Ruiz \& Pav. subsp. deflexa}

Arbusto erecto, glabro. Hojas opuestas y decusadas, coriáceas, resinosas, simples, lanceoladas; márgenes aserrados. Flores en cimas terminales multifloras. Sépalos triangulares, 3-5 $\mathbf{m m}$ long. x 2-3mm lat, glabros. Corola amarillo naranja; elaióforo presente (Fig. 2, G). Anteras amarillas, 2-3,1 mm long., tecas divaricadas (Fig. 3, I).

En Lima mencionada para las provincias de Canta y Huarochirí. Habita en las vertientes occidentales de Lima entre los 2900-3800 m. También en los departamentos de Ancash, Huánuco y La Libertad.

C. deflex a subsp. anneata se diferencia en la forma de las hojas y el color de la corola y está mencionada para Amazonas, Cajamarca, La Libertad y Ancash.

\section{Calceolaria dichotoma Lam.}

Hierba, erecta. Hojas opuestas y decusadas, membranáceas, simples, ovadas; márgenes enteros, aserrados o crenados. Flores en cimas paucifloras o por reducción solitarias. Corola ama- 

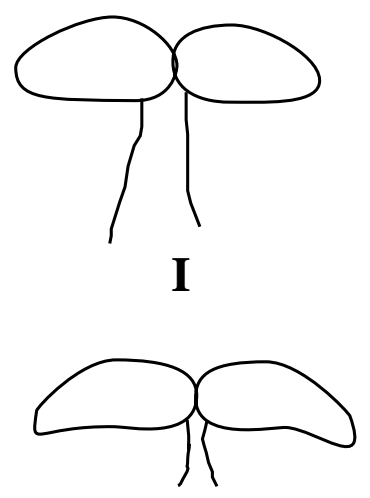

IV
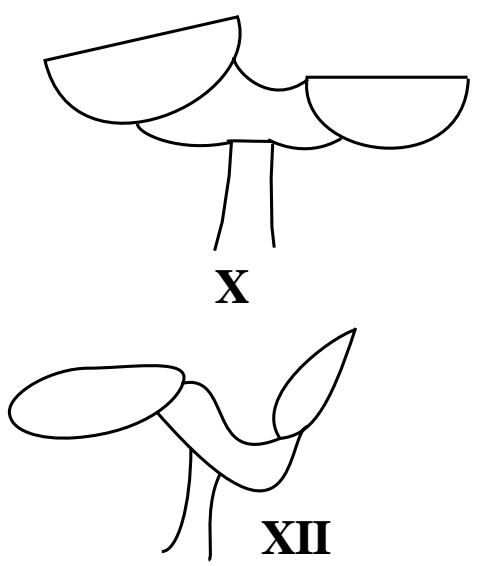

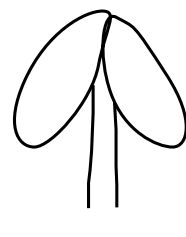

II
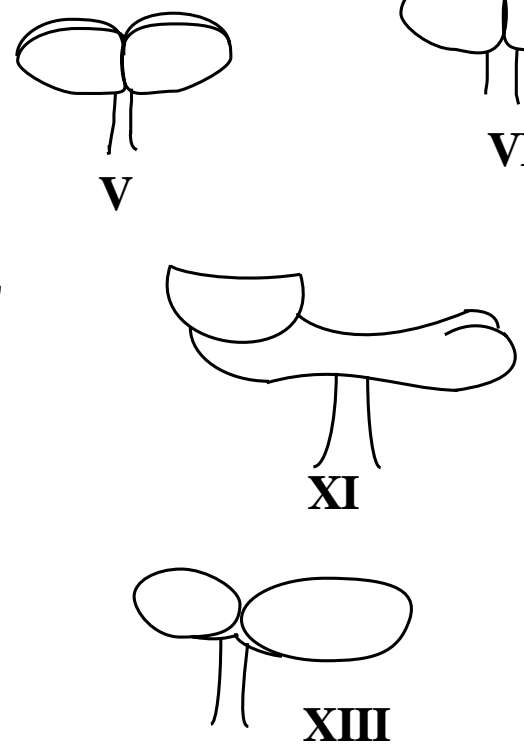

III
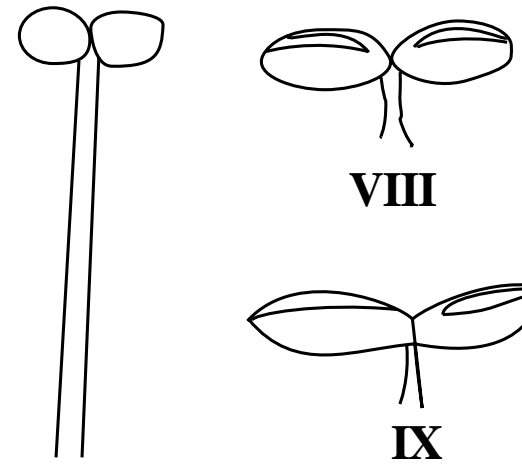

VIII

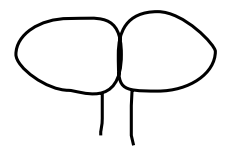

VI

VII
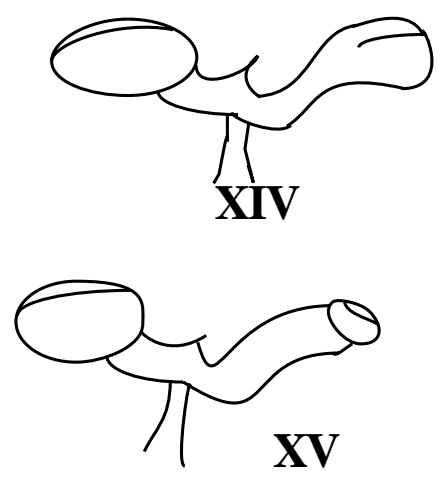

Figura 3. Tipos de estambres en Calceolaria usados en la clave. I-VII: anteras totalmente dehiscentes y con conectivo inconspicuo. VIII-IX: anteras dehiscentes distalmente y con conectivo inconspicuo. X-XIII: anteras con conectivo desarrollado sin diente dorsal. XIV-XV: anteras con conectivo desarrollado y diente dorsal. Dibujo original del autor.

rilla, labio superioracuminado; elaióforo presente (Fig. 2, I a). Anteras amarillas, tecas divaricadas; filamentos varias veces más grandes que las anteras (Fig. 3, VII).

Mencionada para las provincias de Cañete, Huauray Lima en el departamento de Lima. Esta pequeña hierba habita sobre todo en formaciones de lomas, llegando hasta los $1200 \mathrm{~m}$. dealtitud. En el Perú ha sido mencionada además para los departamentos de Amazonas, Arequipa, Ayacucho, Cajamarca, Cusco y Piura.

\section{Calceolaria glauca Ruiz \& Pav.}

Arbusto o subarbusto erecto. Hojas temadas, subcoriáceas, simples, elípticas; márgenes dentados. Flores en cimas multifloras. Corola amarilla; elaióforo presente (Fig. 2, A). Anteras amarillas, 2,2-2,8 mm long., tecas divaricadas (Fig. 3, I).

En Lima hasido recolectada en las provincias de Canta, Huaral, Huarochiríy Yauyos. Bastantefrecuenteen los valles interandinos y en los bordes de caminos, crece entre los 2000-3900 m. En el Perú ha sido mencionada también para Ancash, Cajamarca y Huancavelica.

\section{Calceolaria hispida Benth. subsp. hispida}

Hierba erecta. Hojas opuestas y decusadas, notoriamente pecioladas, membranáceas, lobuladas, ovadas o casi redondas; márgenes serrados o crenados. Flores en cimas paucifloras. Corola amarilla; elaióforo presente (Fig. 2, D ). Anteras amarillas, tecas ligeramente ascendentes (Fig. 3, I).
En el departamento de Lima habita en las provincias de Huarochirí yYauyos, entre los 2600-3000(-4000) m. En el Perú además para Amazonas, Ancash, Arequipa, Ayacucho, Cajamarca, La Libertad y Piura.

C. hispida subsp. acaulis se caracteriza por ser acaule (de ahí el nombre), con hojas en roseta, y está mencionada para La Libertad y Cajamarca.

\section{Calceolaria incarum Kraenzl. subsp. incarum}

Arbusto erecto; corteza exfoliable. Hojas opuestas y decusadas o fasciculadas, subcoriáceas, profundamente lobadas con 4-6 dientes por lado; márgenes revolutos. Flores en cimas terminales multifloras. Corola amarilla con manchas rojizas; elaióforo presente (Fig. 2, D). Anteras amarillas, tecas ligeramente deflexas (Fig. 3, I).

Sólo ha sido recolectada en la provincia de Cajatambo a los 3700 m. También es mencionada para los departamentos de Ancash y Huánuco.

C. incarum subsp. sancheii se diferencia en laformade sus hojasyen su distribución al nortedel Penú(CajamarcayLaLibertad).

\section{Calceolaria inflexa Ruiz \& Pav.}

Hierba o subarbusto escandente; ramas divaricadas; corteza exfoliable en la parte proximal de los tallos. Hojas opuestas y decusadas, herbáceas, simples, ovadas; márgenes crenados. Flo- 
res en cimas multifloras. Corola amarilla; elaióforo presente (Fig. 2, F). Anteras marrones (Fig. 3, V).

Además de la colección tipo proveniente de Canta, y de otra colección a los $2600 \mathrm{~m}$ en esta misma provincia de 1938 (Sandeman 220), C . inflex a no ha vuelto ha ser recolectada en Lima. En el Perú se encuentra en los departamentos de Huánuco, Junín y Pasco.

\section{Calceolaria linearis Ruiz \& Pav.}

Arbusto erecto. Hojas alternas, coriáceas, simples, angostamente elípticas o lineares, 2-2,4 cm long. $x$ 2-2,5 mm lat.; márgenes enteros y revolutos. Flores en cimas terminales multifloras. Corola amarilla, 8-11 mm long.; elaióforo presente (Fig. 2, A). Anteras amarillas o marrones, tecas divaricadas, totalmente dehiscentes (Fig. 3, I).

Sólo seconoce una colección proveniente de Lima (Raimondi 12015). Mencionada además para Ancash, Huánuco, La Libertad y Piura.

\section{Calceolaria lobata Cav.}

Hierba erecta 0 voluble. Hojas opuestas y decusadas, membranáceas, palmatilobadas; márgenes dentados. Flores en cimas terminales multifloras. Corola amarilla con manchas violetas; elaióforo presente (Fig. 2, D). Anteras amarillas, tecas sagitadas (Fig. 3, II).

En el departamento de Lima se encuentra en las provincias de Canta, Huarochirí y Yauyos, entre los 3600-4200 m. En el Perú ha sido mencionada para los departamentos de Ancash, Arequipa, Ayacucho, Moquegua y Puno.

\section{Calceolaria neglecta Molau}

Arbusto pequeño, erecto, corteza exfoliable. Hojas 5,5-10,5 mm long. $\mathbf{x}$ 3-8 $\mathbf{m m}$ lat., opuestas y decusadas (a veces parecen fasciculadas), subcoriáceas, simples, ovadas, algo rugosas; márE genes marcadamente crenados, $\mathbf{6 - 1 1}$ crenas por lado, revolutos. Flores en cimas terminales multifloras. Corola amarilla; elaióforo presente (Fig. 2, B). Anteras amarillas o marrones, tecas divaricadas (Fig. 3, I).

Esta especie fue recolectada en Huarochirí en 1929 (Killip \& Smith 21584) entre los 3000-3500 m y no ha vuelto a ser hallada desde entonces. En el Perú ha sido mencionada para los departamentos de Huancavelica y Junín.

\section{Calceolaria nivalis Kunth subsp. cerasifolia (Benth.) Molau}

Arbusto erecto, glabro, yemas axilares naranja o rojizo lanosas. Hojas opuestas y decusadas, subcoriáceas, simples, ovadas 0 elípticas; márgenes aserrados o dentados; pecíolos rojizos, tomentosos o lanosos. Flores en cimas terminales multifloras. Sépalos ovados, 5-6 mm long. $x$ 3,5-4 mm lat, con un borde tomentoso. Corola amarilla; elaióforo presente (Fig. 2, G). Anteras amarillas, 1,9-2,5 mm long., tecas divaricadas (Fig. 3, I).
Mencionada sólo para la provincia de Huarochirí en Lima. En el Perú esta mencionada además para Amazonas, Ancash, Cajamarca, Lambayeque y La Libertad.

C. nivalis subsp. nivalis difiere en la forma de la hojay la pubescencia de los pecíolos. Ha sido recolectada en Piura en Perú y Ecuador.

\section{Calceolaria pinnata $\mathrm{L}$.}

Hierba higrófita, erecta. Hojas pinnatisectas o pinnadas; márgenes dentados o pinnatífidos. Flores en cimas paucifloras, en individuos poco desarrollados parecen solitarias. Corola amarilla; elaióforo presente (Fig. 2, B). Anteras amarillas, teca anterior de 0,9-1,1 mm long., teca posterior 1,5- $2 \mathrm{~mm}$ long., conectivo elongado 1-1,5 mm long. (Fig. 3, XII).

En Lima habita en las provincias de Barranca, Canta, Cañete, Huaral, Huarochirí, Huaura y Lima. C . pinnata es típica de formaciones de lomas en la costa (150-800 m.), aunque también se le encuentra entre los 2600-3500 m. Ha sido mencionada además para los departamentos de Amazonas, Ancash, A requipa, Cajamarca, Lambayeque, La Libertad y Piura.

\section{Calceolaria pulverulenta Ruiz \& Pav.}

Arbusto pequeño, erecto. Hojas opuestas y decusadas, coriáceas, simples, ovadas u oblanceoladas; márgenes enteros en el extremo proximal, en el distal aserrado o dentado. Corola amarilla con manchas marrón rojizas; elaióforo presente (Fig. 2, E). Anteras amarillas, tecas dehiscentes hasta el conectivo (Fig. 3, IX).

Ausente en herbariosperuanos. No havuelto a ser recolectada desde 1925 en Canta (Pennell 14704, 14740) apesar de las numerosas visitas alazona A diferencia deC. scabra, con laque compartela sección, esta especie habita por debajo de los $3500 \mathrm{~m}$.

\section{Calceolaria rivularis Kraenzl.}

Hierba higrófita, erecta o escandente. Hojas opuestas y decusadas, membranáceas, pinnatífidas; márgenes biserrados. Corola amarilla; elaióforo presente (Fig. 2, D). Anteras amarillas, 6-6,5 mm long., teca posterior 2,5-3 mm long., teca anterior 0,8-1,5 mm long., conectivo conspicuamente elongado 3-4 mm long. con un diente dorsal (Fig. $3, \mathrm{XV}$ )

Sólo se han encontrado algunos especímenes de las provincias de Canta, Huarochirí y Yauyos, entre los 3200-3700 m. En el Perú sólo había sido mencionada para el departamento de Cusco.

\section{Calceolaria rugulosa Edwin}

Subarbusto erecto. H ojas ternadas, membranáceas, simples, ovadas; márgenes aserrados o biserrados. Flores en cimas terminales multifloras. Corola amarilla con manchas moradas; elaióforo presente (Fig. 2, A). Anteras marrones 2-2,2 mm long., tecas divaricadas (Fig. 3, I).

En Lima ha sido mencionada entre los $2600-3900 \mathrm{~m}$ para las provincias de Lima y Canta. Sin embargo, esta especie no se 
recolecta en Lima desde 1973, y los únicos dos ejemplares de este departamento conservados en herbarios nacionales (USM) datan de 1875 (Raimondi 7814, 8058). En Perú ha sido mencionada además para los departamentos de Ancash, Arequipa, Cajamarca, Huancavelica, Lambayeque, La Libertad y Piura.

\section{Calceolaria rupestris Molau}

Arbusto erecto. Hojas opuestas y decusadas, subcoriáceas, simples, angostamente elípticas o lineares, 0,8-1,6 cm long. $\mathrm{x}$ 1,8-2,1 mm lat.; márgenes enteros y revolutos. Flores en cimas terminales multifloras. Corola amarilla; elaióforo presente (Fig. 2, E). Anteras amarillas, tecas divaricadas, dehiscentes hasta el conectivo (Fig. 3, VIII).

Conocida sólo para la provincia de Yauyos en Lima, a los $3900 \mathrm{~m}$. Para el Perú ha sido mencionada además en los departamentos de Ayacucho, Huancavelicay Junín.

\section{Calceolaria scabra Ruiz \& Pav.}

Hierba o arbusto pequeño, erecto. Hojas opuestas y decusadas, membranáceas, simples, ovadas o elípticas; márgenes crenados, 3-5 crenas por lado, algo revolutos. Corola amarilla con algunas manchas marrón rojizas; elaióforo presente (Fig. 2,E). Anteras amarillas, tecas dehiscentes hasta el conectivo (Fig. 3, IX).

Aunque fue recolectada en las provincias de Huaral (Wilkes s.n.) y Huarochirí en 1922 (Macbride \& Featherstone662) y 1940 (Asplund 11453; 11471), ninguno de estos ejemplares se encuentra en herbarios nacionales. Esta especie habita en estepa de gramíneas sobre los $3600 \mathrm{~m}$ alcanzando su máxima altitud en la puna, a los $4400 \mathrm{~m}$. En el Perú ha sido citada para los departamentos de Ayacucho, Huancavelicay Junín.

\section{Calceolaria scapiflora (Ruiz \& Pav) Benth.}

Hierbas acaules, $6-16 \mathrm{~cm}$ alto. $\mathrm{Hojas}$ en rosetas, membranáceas, simples, ovadas o espatuladas; márgenes enteros, crenados o aserrados. Flores solitarias sostenidas por un tallo central escapiforme. Corola amarillo intenso con numerosas manchas violetas; elaióforo ausente (Fig. 2, J). Anteras marrones 0 violetas, tecas totalmente ascendentes (Fig. 3, III).

En Lima habita entre los 3600-4200 m. Ha sido recolectada en la provincia de Canta y además se ha reportado para las provincias de Oyón (D ombey 314) y Huarochirí (Sandeman 79), material que se encuentra en herbarios extranjeros. En el Perú ha sido mencionada además para los departamentos de Apurímac, Cusco, Huancavelica, Huánuco, Junín, Limay Pasco.

\section{Calceolaria tenuis Benth.}

Hierba higrófita, erecta. Hojas opuestas y decusadas, membranáceas, pinnatífidas o pinnadas; márgenes aserrados, dentados o lobados. Flores en cimas paucifloras, en individuos poco desarrollados aparentemente solitarias. Corola amarilla, elaióforo presente (Fig. 2, B). Anteras amarillas, teca anterior 0,6-0,8 mm long., teca posterior 1-1,2 mm long., conectivo ligeramente alargado 0-0,3 mm long. (Fig. 3, X III).
En Lima se ha reportado para las provincias de Canta, Huarochirí y Yauyos. Esta especie se encuentra siempre cerca de corrientes de agua 0 asociada a musgos en lugares húmedos entre los 2200-3900 m. En el Perú tiene amplio rango, así se sabe de su presencia en Ancash, A requipa, Ayacucho, Cusco, Huancavelica, Huánuco, Junín y Puno.

\section{Calceolaria tripartita Ruiz \& Pav.}

Hierba higrófita, erecta o escandente. Hojas opuestas y decusadas, membranáceas, pinnatífidas; márgenes aserrados o biserrados. Flores en cimas multifloras. Corola amarilla; elaióforo presente (Fig. 2, B). Anteras amarillas, teca posterior fértil, 2,5 mm long., teca anteriorabortada, conectivo prolongado, 3-3,2 mm long. con un diente dorsal (Fig. 3, XIV).

En Lima ha sido mencionada para las provincias de Barranca, Canta, Lima, Huaura, Huarochirí y Yauyos. C. tripartita es una especie bien distribuida, frecuente en formaciones de lomas entre los 500-900 m.; y en los andes cerca de cursos de agua entre los 1800-3900 m. En el Perú se encuentra en numerosos departamentos: Amazonas, Ancash, A purímac, Ayacucho, Cajamarca, Cusco, Huancavelica, Huánuco, Junín, La Libertad, Lambayeque, Pasco, Piuray Puno.

\section{Calceolaria utricularioides Benth.}

Hierbapequeña, 7-30 cm alto, erecta. Hojas opuestas y decusadas, membranáceas, simples; márgenes enteros o dentados. Flores en cimas paucifloras o en individuos poco desarrollados aparentemente solitarias. Corolablanco-amarillenta, labios equilongos; elaióforo ausente(Fig. 2,C).Anteras amarillas, tecas divaricadas; filamentos varias vecesmásgrandesquelasanteras(Fig. 3, VII).

En Lima ha sido recolectada en las provincias de Canta, Huarochirí L Lima. A diferencia de C . dichotoma, con quien compartela sección M icranthera, esta especie se encuentra en estepa de gramíneas con arbustos dispersos, entre los 2800-3600 m. En el Perú su distribución se limita a los departamentos de A mazonas, Ancash, Cajamarca, La Libertad y Piura.

\section{Calceolaria virgata Ruiz \& Pav.}

Subarbusto erecto o escandente. Hojas opuestas y decusadas, membranáceas, simples, ovadas; márgenes aserrados. Flores en cimas terminales multifloras. Corola amarilla con una franja morada; elaióforo presente (Fig. 2, A). Anteras amarillas o marrones, 1,8-2,8 mm long., tecas divaricadas (Fig. 3, I).

En Lima habita en las vertientes occidentales, mencionada para las provincias de Canta, Huaral, Huarochirí, O yón y Yauyos entre los (1800-)2400-3900 m. D ebido a su amplia distribución se encuentra también en Amazonas, Ancash, Apurímac, Ayacucho, Cajamarca, Cusco, Huancavelica, Huánuco, Junín, La Libertad, Pasco, Piuray Puno.

\section{Calceolaria viscosa Ruiz \& Pav.}

Arbusto 1-2 m. alto, erecto. Hojas opuestas y decusadas, co- 
riáceas, resinosas, simples, glabras; márgenes dentados. Flores en cimas terminales multifloras. Corola amarilla, elaióforo presente (Fig. 2, E). Anteras amarillas, 4-4,8 $\mathbf{~ m m}$ long., tecas divaricadas (Fig. 3, I).

Recolectada en Lima entre 0 tuto y O yón por Raimondi (antes de 1900) y a los $3500 \mathrm{~m}$ en la provincia de Cajatambo en 1975 (Zimny s.n.). En el Perú se encuentra además en los departamentos de Ancash, Huánuco y La Libertad.

\section{Discusión y Conclusión}

Con el presente trabajo, ascienden a 29 las especies de C aloeolaria para Lima. C . rivularis, registrada sólo para Cusco, es mencionada por primera vez para este departamento. Los ejemplares revisados de esta especie habían sido determinados como C. tripartita, aun cuando presentan la teca anterior de las anteras fértiles, principal diferencia entre ambas especies.

O tras especies como C. bicrenata, C. inflex a, C. linearis, C. neglecta, C. pulverulenta y C. scabra fueron mencionadas para Lima en una o pocas colecciones que no se encuentran en herbarios nacionales. Algunas de ellas, como C . linearis no han sido recolectadas en Lima desde la época de Raimondi, en la segunda mitad del siglo XIX; o como en el caso de C. pulverulenta, desde comienzos del siglo pasado por Pennell. Todas estas especies se encuentran distribuidas en otros departamentos, donde han sido recolectadas en años recientes, y son consideradas (a excepción C. pulverulenta y C. neglecta) como especies de preocupación menor (Salinas \& León, en prensa). C. pulverulenta, cuya única localidad mencionada además de Lima es Yungay (Ancash), no ha vuelto a ser recolectada desde 1948 y es considerada vulnerable (Salinas \& León, en prensa). A simismo, C . neglecta es también considerada en estado de vulnerabilidad (Salinas \& León, en prensa), debido a que la mayoría de sus ejemplares de herbario provienen de la cuenca alta del Mantaro.

En cuanto a la subdivisión del género y su representatividad en este departamento, las especies encontradas en Limapertenecen a dos subgéneros y trece secciones de Caloolaria (Anexo 1). El subgénero $C$ alooolaria está representado por doce secciones y 27 especies; las dos especies restantes pertenecen a una sección del subgénero Cheilonoos (Wettst.) Pennell. La sección con mayor número de especies es $C$ alooolaria, sección que presenta el rango de distribución más amplio en el género. En cuanto a las demás secciones, unadelas tres especies delasección E rioides se encuentra en Lima; dos de las cuatro especies de Micranthera; una de las tres especies de Scapiflora; y una de las dos especies de V erticillatae. Ninguna sección se encuentra restringida a este departamento.

En cuanto al rango altitudinal en Lima, aproximadamente el 83\% de las especies de Caloolaria habitan entre los 3000-3900 m, franja que corresponde a la estepa de gramíneas con arbustos dispersos. Entre los 1200-1800 m, piso de cactáceas columnares, no se ha recolectado ninguna especie. Cinco especies habitan por debajo de los $1000 \mathrm{~m}$, en lomas, aunque sólo una (C. dichotoma) está restringida a esta formación vegetal. El resto reaparece a partir de los $1800 \mathrm{~m}$. Finalmente, sólo cuatro especies (C . annua, C. lobata, C. scabra y C. scapiflora) sobrepasan los $4000 \mathrm{~m}$ y son capaces de habitar en la puna. No se encontraron datos de altitud para C. linearis ni C. nivalis ssp. nivalis.

Molau (1988) señaló la deflexión de Huancabamba como la barrera de dispersión más importante para este género. D ebido a esto encontramos en los departamentos del norte del Perú la mayor diversidad de especies y endemismos de C alcoolaria. Así por ejemplo, Amazonas y Cajamarca son los que poseen mayor número de especies, 36 y 57 respectivamente. En cuanto al centro de nuestro país, también existen varias especies endémicas. Lima, es el séptimo departamento contando con aproximadamente el $21 \%$ de las especies presentes en el Perú.; y aunque no hay especies restringidas a este departamento, C. annua y C. aperta ssp. aperta son endémicas de Limay Ancash. Además, dentro de este departamento, las provincias de Cantay Huarochiní son las que presentan un mayor número de especies.

Las especies de C alcoolaria en Lima son conocidas comúnmente como «zapatitos» 0 «globitos», y C. linearis se conoce también como «romero silvestre» (Soukup, 1986). No se han reportado usos específicamente para este departamento; sin embargo, se sabe que C. pinnata y C. aneiformis son usadas como diuréticas; C. aneiformis además para tratar afecciones uterinasy para quitar manchas de la piel y cicatrices; yC . deflexa en la preparación de llipta para chacchar coca (Soukup, 1986; Brack, 1999; Mostacero etal., 2002).

\section{Agradecimientos}

Agradezco a la Christensen Fund por la ayuda financiera brindada para la revisión del herbario y biblioteca del Missouri Botanical Garden. De igual manera extiendo mi reconocimiento a los curadores de los herbarios MO, MO L y USM por las facilidades brindadas en la revisión del material. Asimismo, a Arturo G randa por la revisión del manuscrito.

\section{Literatura citada}

Andersson, S. 2006. On the phylogeny of the genus Calceolaria (Calceolariaceae) as inferred from ITS and plastid matK sequences. Taxon 55(1): 125-137.

Brack, A. 1999. Diccionario Enciclopédico de Plantas Útiles del Perú. Ed. Centro Bartolomé de las Casas, Perú.

Brako, L. \& J. Zarucchi. 1993. Catalogue of the Flowering Plants and Gymnosperms of Peru. Monogr. Syst. Bot. Missouri Bot. Gard. 45: 1-1286.

Edwin, G. 1970. New taxa and notes on the Scrophulariaceae of Peru. Phytologia 19(6): 361-406.

Edwin, G. 1971. Scrophulariaceae. In: J. F. Macbride, Flora of Peru. Publ. Field Mus. Nat. Hist., Bot. Ser. 13 (5B/3):459717.

Fischer, E. 2004. Scrophulariaceae. Fam. Gen. Vasc. Pl. 7: 333-432. López Guillén, J. 1968. La sección Aposecos del Subgénero Calceolaria Pennell en el Perú. Primera revisión de las especies endémicas Peruanas. Raymondiana 1:29-88.

López Guillén, J. 1969. La sección Aposecos del Subgénero Calceolaria Pennell en el Perú. Segunda revisión de las especies endémicas peruanas. Raymondiana 2: 5-44.

Molau, U. \& I. Sánchez. 1986. Calceolaria (Scrophulariaceae): Las especies del dpto. de Cajamarca, Perú. Bol. Lima 43 (8): 37-51.

Molau, U. 1988. Scrophulariaceae. Part I. Calceolarieae. Fl. Neotrop. 47: 1-326.

Mostacero, J.; F. Mejía \& O. Gamarra. 2002. Taxonomía de las Fanerógamas Útiles del Perú. Editora Normas Legales SAC. Lima. 2: 801-815.

Olmstead, R.; C. de Pamphilis; A. Wolfe; N. Young; W. Elisons \& P. Reeves. 2001. Disintegration of the Scrophulariaceae. Am. J. Bot. 88 (2): 348-361.

Pennell, F. W. 1945. The genus Calceolaria in southeastern Peru. Proc. Acad. Nat. Sci. Philadelphia 97: 137-177. 
Pennell, F. W. 1951. The united-leaved calceolarias of the northern and middle Andes (Scrophulariaceae). Notul. Nat. Acad. Nat. Sci. Philadelphia 236: 1-3.

Puppo, P. 2005. Estudio Taxonómico del género Calceolaria L. en la Cuenca alta y media del Río Chillón-Provincia de Canta. Tesis para optar el título de Biólogo. Universidad Nacional Agraria La Molina. Perú. 108 pp.

Salinas, I. \& B. León. En prensa. En: B. León et al. (Ed.) «Libro Rojo de las Plantas Endémicas del Perú».

Soukup, J. 1986. Vocabulario De Los Nombres Vulgares De La Flora Peruana y Catálogo De Los Géneros. Editorial Salesiana. Lima.

Vogel, S. 1974. Ölblumen und Ölsammelnde Bienen. Trop. Subtrop. Pflanzenwelt 7: 282-547.

Weberbauer, A. 1945. El Mundo Vegetal de los Andes Peruanos. Estac. Exper. Agric. La Molina. Edit. Lumen. Lima, Perú.

\section{Anexo 1}

Lista de las especies registradas para el departamento de Lima señalando la sección a la que pertenecen (Molau, 1988).

\begin{tabular}{|c|c|}
\hline Sección & Especie \\
\hline A nacyrta & $\begin{array}{l}\text { C. glauca Ruiz \& Pav. } \\
\text { C. rugulosa Edwin } \\
\text { C. virgata Ruiz \& Pav. }\end{array}$ \\
\hline Calceolariae & $\begin{array}{l}\text { C. annua Edwin } \\
\text { C. chelidonioides Kunth } \\
\text { C. pinnata L. subsp. pinnata } \\
\text { C. rivularis Kraenzl. } \\
\text { C. tenuis Benth. } \\
\text { C. tripartita Ruiz \& Pav. }\end{array}$ \\
\hline Ericoides & C. linearis Ruiz \& Pav. \\
\hline Lobatae & $\begin{array}{l}\text { C. hispida Benth. subsp. hispida } \\
\text { C. incarum Kraenzl. subsp. incarum } \\
\text { C. lobata Cav. }\end{array}$ \\
\hline M icranthera & $\begin{array}{l}\text { C. dichotoma Lam. } \\
\text { C. utricularioides Benth. }\end{array}$ \\
\hline Parvifoliae & $\begin{array}{l}\text { C. cuneiformis Ruiz \& Pav. subsp. cuneiformis } \\
\text { C. neglecta Molau }\end{array}$ \\
\hline Polyclada & C. inflexa Ruiz \& Pav. \\
\hline Revolutae & C. rupestris Molau \\
\hline Salicifoliae & $\begin{array}{l}\text { C. deflexa Ruiz \& Pav. subsp. deflexa } \\
\text { C. nivalis Kunth subsp. cerasifolia (Benth.) Molau } \\
\text { C. viscosa Ruiz \& Pav. }\end{array}$ \\
\hline Scapiflorae & C. scapiflora (Ruiz \& Pav.) Benth. \\
\hline Teucriifolia & $\begin{array}{l}\text { C. pulverulenta Ruiz \& Pav. } \\
\text { C. scabra Ruiz \& Pav. }\end{array}$ \\
\hline U rticopsis & $\begin{array}{l}\text { C. aperta Edwin subsp. aperta } \\
\text { C. bicolor Ruiz \& Pav. } \\
\text { C. bicrenata Ruiz \& Pav. }\end{array}$ \\
\hline V erticillatae & C. angustiflora Ruiz \& Pav. \\
\hline
\end{tabular}


http://sisbib.unmsm.edu.pe/BVRevistas/biologia/biologiaNEW.htm 